\title{
O DESPERTAR DO POVO TERENA PARA OS SEUS DIREITOS: MOVIMENTO INDÍGENA E CONFRONTO POLÍTICO EM MATO GROSSO DO SUL ${ }^{1}$
}

\author{
Luiz Henrique Eloy Amado²
}

\begin{abstract}
RESUMO: O presente texto aborda o "tempo do despertar" do Povo Terena, configurado pelo momento atual do Conselho Terena. São reflexões iniciais com base em etnografia dos processos das retomadas de terras levado a cabo pelas lideranças Terena de Mato Grosso do Sul. Valendo-se de trajetórias de mobilização e decisões políticas no âmbito das Assembleias Terena, o texto oportuniza trazer à baila a discussão da presença Terena nos escritos etnográficos e como categorias presente nesta discussão podem ser rearticuladas e contribuir para a antropologia enquanto ciência e o papel do pesquisador tendo em vista que o autor pertence ao povo Terena.
\end{abstract}

Palavras-chave: Território indígena. Conselho Terena. Mobilização Política.

Kali emó 'uti: Enepora yutoití hara koyuhó "kónokea iyukeovo visonéu" xapakuke viyenó têrenoe. Ainovo isonêuti koyúhoti koêku vaokopeovó poké'exa ke ûti xapakukéhiko nâti xapa ûti yara vovóku Mato Grosso do Sul. Koyuhoa maka kixóvoku vitukeovó ya heu kôeti isonêuti, ya política, ya vipúxeovo xoko Hánaiti Ho’únevo Têrenoe, enepora yutoiti koyuhôatimakamo vapeyea ûti Têrenoe ya yitoiti xoko koyuhópetihiko kixoku vitukeovó. Yane'é vopósikopa koêku ho'úxopeovo enepora isonêuti koané enepora yutoxópoati kali emo'úti viyenó têrenoe.

Ukéaku ra emó’uti: Poké'exa kopenoti, Hanaiti Ho’únevo Têrenoe, Kixoku visonéu ya política.

\footnotetext{
${ }^{1}$ Este texto é parte integrante de pesquisa de doutorado em andamento que tem como título "Vukápanavo: Etnografia dos processos de territorialização e usos da terra pelos Terena de Taunay-Ipegue, Mato Grosso do Sul", desenvolvido no âmbito do Programa de Pós-graduação em Antropologia Social do Museu Nacional, UFRJ.

${ }^{2}$ Indígena Terena da Aldeia Ipegue. Advogado, doutorando em antropologia social - Museu Nacional/UFRJ. Endereço eletrônico: adv.luizeloy@gmail.com.
} 
ABSTRACT: This article addresses and analyses the "time of awakening" of the Terena people as it can be seen in the current moment of the Terena Council. It presents initial reflections on this process based on an ethnography of land reclaimings undertaken by Terena leaderships in Mato Grosso do Sul. Based on the analysis of trajectories of mobilization and political decisions made in the Terena Assemblies, the text examines how the Terena people have been portrayed in ethnographic writings and discusses how the categories used in these writings can be rearticulated in order to contribute to the development of an anthropology that is based on sound scientific methods of inquiry. It also discusses the role of the researcher, considering that the author is part of the Terena people.

Keywords: Indigenous territory. Terena Assembly. Political mobilization.

\section{Considerações Iniciais}

Considero que quando um pesquisador indígena escreve sobre seu povo é momento oportuno para reiterar justificativas que nos motiva a seguir a lógica da produção imposta pela academia, produto da sociedade não indígena. Parte do que socializo neste texto está presente na tese de doutorado que desenvolvi junto ao programa de pós-graduação do Museu Nacional. A primeira justificativa que apresento é de ordem pessoal. Lembro-me do meu ingresso no doutorado, quando a banca me questionou o porquê de estudar o meu próprio povo, já que é corrente tradicional na antropologia estudar o "outro". Neste ponto resgato minha história de vida, calcado na minha origem, pois não é possível fazer esse dissociamento. Para nós, pesquisadores indígenas a única razão de deixar a aldeia e ingressar na universidade é ter a certeza que poderemos nos apropriar desses "ditos conhecimentos científicos" e de alguma maneira usá-los em prol de nosso povo. A isto se alia a justificativa de ordem acadêmica. É a oportunidade do pesquisador indígena, enquanto porta voz de seu povo, falar em nome dele. Como é corrente entre nós Terena a expressão “já chega do purutuyê [branco] falar por nós! Nós temos que falar por nós agora, é para isso que enviamos nossos jovens para as universidades, para competir de igual"3. Além disso, a passagem pela academia é momento oportuno para (re) ver tudo o que foi escrito sobre nós pelos purutuyê $\hat{e}^{4}$. A terceira justificativa é de ordem social, pois além de refletir criticamente sobre o tratamento histórico dado aos povos indígenas e sobre as relações interétnicas estabelecidas com o purutuyê, faz-se necessário assentar balizas que demonstrem como o saber dito científico aliado ao conhecimento tradicional pode contribuir para o

\footnotetext{
${ }^{3}$ Neste sentido me apoio nas falas das lideranças Lindomar Terena, Célio Fialho, Alberto França, Estevinho Tiago, Simone Eloy, Zuleica Tiago, Manoel Amado, Eder Alcântara Oliveira, Arildo Alcântara, Juciney Alcântara Bernardo e Elvisclei Polidório.

${ }^{4}$ Branco, no idioma Terena, se referindo aquele que não é indígena.
} 
reconhecimento de direitos, especialmente o direito originário sobre os territórios tradicionalmente ocupados.

É preciso ainda refletir sobre a contribuição dos escritos indígenas para a ciência, olhando para o pressuposto teórico indígena consistente no território tradicional como direito fundamental dos povos indígenas, sendo impossível abordar qualquer discussão referente a direitos sociais, sem necessariamente tratar desses territórios. Outro aspecto é entender as relações interétnicas estabelecidas pelos povos indígenas com a sociedade não indígena ao longo do avanço e consolidação das frentes de expansão agrícola e pastoril, no caso do povo Terena referente à instalação dessas frentes no Mato Grosso do Sul e, deixar evidente que mesmo diante dessas investidas capitalistas, os Terena nunca perderam o vínculo com seus territórios. As alianças políticas estabelecidas com outros povos indígenas e até mesmo com os não indígenas (purutuyê) se deram acima de tudo no único intuído de se manter e permanecer como povo, ainda que para isso tiveram que acionar outros símbolos e outros elementos culturais.

O estado de Mato Grosso do Sul concentra atualmente a segunda maior população indígena do Brasil, destacando-se os seguintes povos: Terena, Guarani Nhandeva, Guarani Kaiowá, Kadiwéu, Kinikinau, Guató, Atikum, Kamba e Ofaié. Atualmente, as comunidades indígenas sofrem com problemas sociais de várias ordens, que incluem a educação, desassistência a saúde, violência e desnutrição. Toda essa problemática está intimamente ligada à questão territorial, resultado de processos de perda da terra que se deu de maneiras diferentes em relação a cada povo.

O povo Terena têm seu território localizado no oeste de Mato Grosso do Sul, coincidindo com parte do ecossistema do Pantanal, nos municípios de Miranda, Aquidauana, Anastácio, Sidrolândia, Dois Irmãos do Buriti, Nioaque e Rochedo. Segundo o Censo Demográfico de 2010, a população Terena é composta de aproximadamente 28 mil habitantes, distribuída por 10 Terras Indígenas, com mais de 40 aldeias ${ }^{5}$. O povo Terena faz parte da família linguística Aruak, e por isso, apresenta várias características socioculturais resultantes dessa tradição, como a cerâmica e a prática da agricultura.

\footnotetext{
${ }^{5}$ Dados escolares: Fazem parte do Território Etnoeducacional Povos do Pantanal contando com 26 escolas, das quais 15 municipais e 11 estaduais, somando 6.364 alunos matriculados na Educação Básica (Pré-escola: 479; Ensino Fundamental - anos iniciais e finais: 4.197; Ensino Médio: 938; EJA Ensino Fundamental e Médio: 820) e aproximadamente 250 professores.
} 
Mapas: Localização de Mato Grosso do Sul e municípios com área indígena ${ }^{6}$
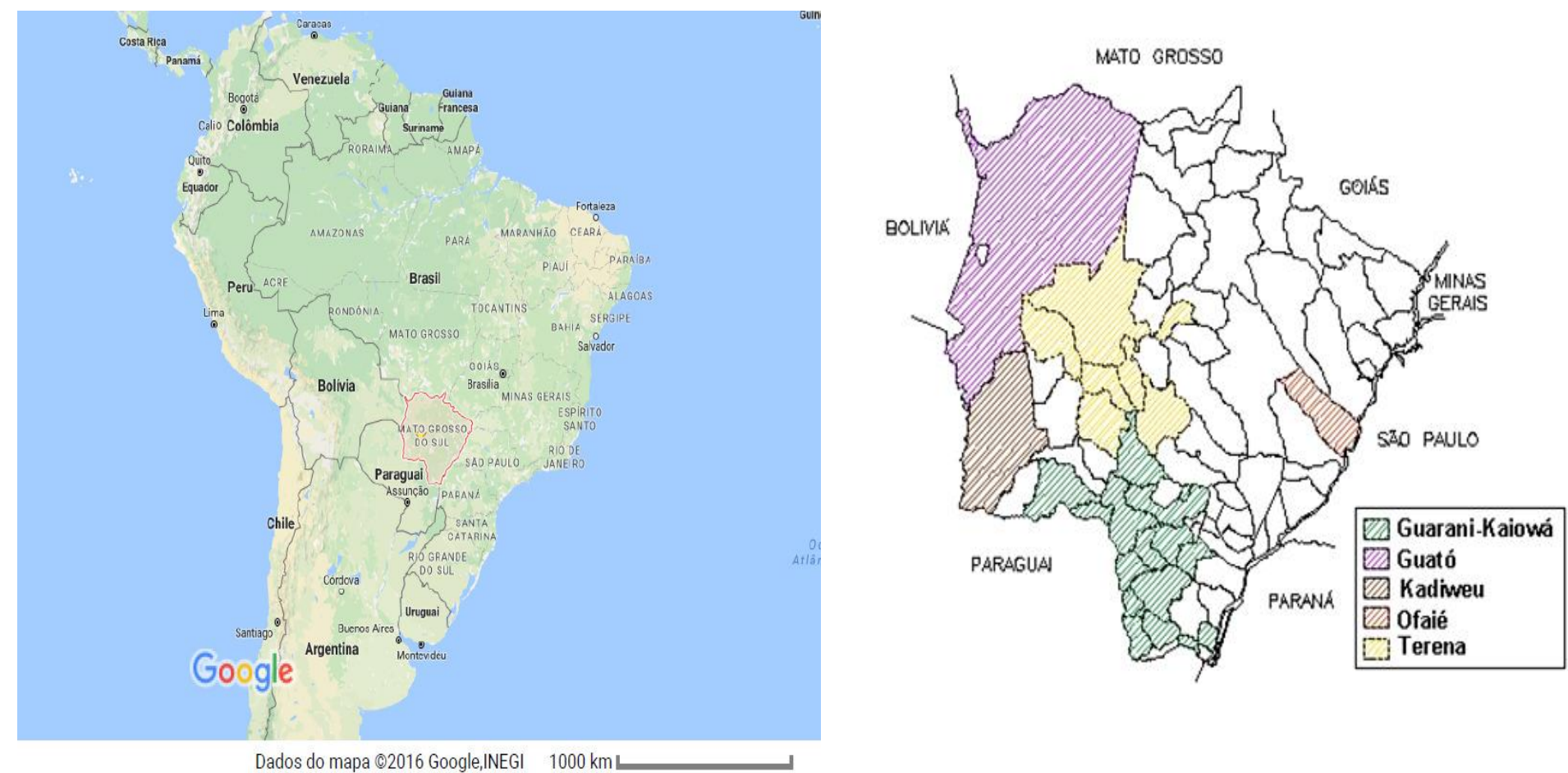

Fonte: Programa Kaiowá - Guarani / NEPPI-UCDB. Geoprocessamento - Celso Smaniotto, 2007.

As áreas ocupadas atualmente são espaços de terras que foram reservadas, fruto da política oficial do Estado brasileiro adotado no início do século passado. Tais reservas federais são denominadas "terra indígena", categoria jurídica instituída pelo estatuto do índio (Lei n. 6.001 de 1973). Assim, temos as seguintes terras indígenas: Taunay-Ipegue, Limão Verde, Cachoeirinha, Pilad Rebuá, Lalima, Nioaque, Buriti, Aldeinha, Tereré e N.S. Fátima. Além dessas terras indígenas, registramos ainda a presença da população terena em agrupamentos constituídos em áreas urbanas no município de Campo Grande, bem como na reserva indígena de Dourados, na terra indígena dos Kadiwéu no município de Porto Murtinho e nos estados de São Paulo e Mato Grosso.

Segundo os escritos antropológicos, a etnia Terena é um subgrupo Guaná ou Chané, da família linguística Aruak. "Os antigos Guaná falavam, até o período anterior à guerra entre o Paraguai e a Tríplice Aliança (1864-1870), diversos dialetos Aruák. Estavam

\footnotetext{
${ }^{6}$ Programa Kaiowá - Guarani / NEPPI-UCDB. Geoprocessamento - Celso Smaniotto, 2007.
} 
divididos nos subgrupos Terena (Etelenoé), Echoaladi ${ }^{7}$, Quiniquinau (Equiniquinau) e Laiana (Layana)" (EREMITES DE OLIVEIRA E PEREIRA, 2003, p. 242).Tradicionalmente ${ }^{8}$, os textos que abordam a história do povo Terena adotam a divisão da linha do tempo sistematizada por Circe Maria Bittencourt e Maria Elisa Ladeira (2000), no livro A História do Povo Terena, seguindo: 1) os Tempos Antigos se estendiam até o final da Guerra contra o Paraguai; 2) os Tempos de Servidão correspondiam ao período entre o final da Guerra contra o Paraguai e a formação das Reservas no início do século XX; 3) os Tempos Atuais estariam situados após a formação das Reservas. O pesquisador terena Claudionor do Carmo Miranda (2006), em sua dissertação intitulada Territorialidades e práticas agrícolas: premissas para o desenvolvimento local em comunidades terena de $M S$, acrescentou a essa linha um quarto período: Tempo do Despertar, caracterizada pela “inserção dos 'patrícios' Terena nos espaços que antes não eram ocupados por eles, na economia regional, por exercerem cargos públicos ou serem profissionais liberais e pela presença dos jovens Terena nas universidades" (MIRANDA, 2006, p. 22) ${ }^{9}$. Entretanto, neste texto, a partir da leitura do material disposto, dos documentos que tive acesso e dos relatos colhidos, reformulo esses tempos históricos do povo Terena, inclusive no que tange ao Tempo do Despertar formulado por Miranda (2006).

O antropólogo Roberto Cardoso de Oliveira (1968) trabalhou a história do povo Terena em dois momentos - sociedade Terena tradicional e moderna pós-guerra -, estes divididos pelo grande acontecimento a Guerra do Paraguai. Esta linha foi seguida por Gilberto Azanha (2004, p. 22) quando da elaboração do estudo de identificação e delimitação de Taunay-Ipegue. Anteriormente, Altenfelder Silva (1949) havia trabalhado a história do povo Terena em quatro períodos principais: $i$. A introdução e instalação definitiva dos Terena no Brasil; ii. Da instalação ao início da Guerra do Paraguai; iii. Desde a Guerra do Paraguai até a fundação do Serviço de Proteção aos Índios, em 1910; iv. Período contemporâneo.

Como dito, o pesquisador Terena Claudionor Carmo Miranda, além desses tempos históricos, acrescentou "o tempo do despertar" se referindo ao momento da década de 1990,

\footnotetext{
${ }^{7}$ No livro Do índio ao bugre: o processo de assimilação dos Terena, o antropólogo Roberto Cardoso de Oliveira (1976), a partir de escritos de cronistas dos séculos XVIII e XIX, como Sanches Labrador, Félix Azara, Juan Francisco Aguirre, Francis de Castelnau, Alfredo D' Escragnolle Taunay, considera que o subgrupo Echoaladi foi designado como Guaná em algumas obras. Devido a imprecisões como essas, é necessário ter cautela na interpretação dos dados. A designação dos diversos grupos indígenas não era uniforme e, não se pode inferir exatamente os mesmos etnônimos para a atualidade (XIMENES, 2017, p. 31).

${ }^{8}$ Em minha dissertação de mestrado também segui essa divisão. No entanto, desde aquele momento essas temporalidades históricas me causavam certa "estranheza", por isso decidi no doutorado aprofundar esta questão, ainda mais por conta dos impactos concretos nos processos judiciais.
}

${ }^{9}$ Neste mesmo sentido Ximenes (2017). 
marcado pela crescente escolarização universitária entre os Terena e pela ocupação de cargos públicos. Entretanto, a partir da pesquisa realizada no âmbito do doutorado trabalhei outros tempos da história Terena, a saber: a) sociedade Terena no sistema Chaco Paraguai-Pantanal, e sua relação com os Mbaya / Guaycuru; b) sociedade Terena e sua relação com a coroa portuguesa; c) tempo do Esparramo: O período da Guerra do Paraguai (1864 - 1875); d) o pós-guerra - ruptura com o modo de vida Terena, expropriação de seus territórios, primeiras retomadas Terenas e período de servidão; e) confinamento - criação das reservas, política do SPI, assimilação; f) projetos de desenvolvimento que impactaram a vida das comunidades Terena (linha telegráfica, estrada de ferro e gasoduto); g) período da ditadura militar - várias violações aconteceram nas aldeias Terena; h) período da Constituinte - participação Terena no movimento indígena nacional; i) década de 90: a escola na sociedade Terena e processo decisório; j) década de 2000 - da aldeia para a universidade; 1) o despertar do Povo Terena para os seus direitos $(2010$ - 2017): movimento de retomada do território tradicional. Nota-se, que ao contrário do que defendeu Miranda (2006), pondero que o Tempo do Despertar do povo Terena foi marcado pela efetiva luta pelo seu território tradicional, coincidindo exatamente com o momento da pesquisa.

A partir da categoria Fricção interétnica é possível analisar como se deu o relacionamento do povo Terena tanto com os purutuyê, quanto com os outros povos indígenas com quem estabeleceram alianças. Com base em aportes iniciais é possível também constatar como fatores externos, ligados ao colonialismo e ao imperialismo impactaram profundamente a vida da sociedade Terena. Os textos consultados dão conta de uma sociedade denominada na etnologia como sociedade antiga totalmente diferente da atual, mas que nem por isso o povo Terena desapareceu. O material bibliográfico disponível sobre o denominado "tempos antigos", anterior ao século XIX é sobremaneira escasso. Temos, pois, no século XVIII, a obra clássica de Sánchez Labrador ${ }^{10}$, e no século XIX as obras de Francis de Castelnau, Taunay e Bach. Aparecem no século seguinte os escritos de Kalervo Oberg, Fernando Altenfelder Silva ${ }^{11}$, Herbert Baldus e Roberto Cardoso de Oliveira. Tradicionalmente, os autores que escreveram sobre os Terena tentam descrever a antiga sociedade Terena, ora

\footnotetext{
${ }^{10}$ Roberto Cardoso de Oliveira aponta que "a obra clássica de Sáchez Lavrador, trata unicamente dos índios Guaná ou Txané, dos quais os Terena constituem subgrupo, sem, contudo, mencioná-los de modo específico" (OLIVEIRA, 1968, p. 17).

${ }^{11}$ É autor do texto intitulado "Mudança cultural dos Terena", publicado em 1949 na Revista do Museu Paulista. Esteve na aldeia Bananal, município de Aquidauana, na primeira semana de junho de 1946, permanecendo ali por duas semanas. E também de dezembro de 1946 a fevereiro de 1947, oportunidade em que realizou pesquisa de campo entre os Terena de Bananal.
} 
analisando os aspectos culturais daquele momento histórico notadamente marcado pelo domínio da agricultura ${ }^{12}$ e a relação interétnica estabelecida com outros povos que habitavam o Chaco como fez Fernando Altenfelder (1949), ora analisando a estrutura e organização social como fez Roberto Cardoso de Oliveira (1968), que baseando-se em dados empíricos, chegou à conclusão de que a estrutura tradicional Terena não sobreviveu ao contato interétnico ${ }^{13}$.

Outro ponto importante tanto para o povo Terena, quanto para a antropologia e história é o debate a partir das reflexões em torno do colonialismo interno, desenvolvimentismo e resistência Terena. González Casanova (1963), indica que os primeiros apontamentos sobre colonialismo interno encontramos na obra de Lênin ${ }^{14}$, pois este estava interessado em expor a solução do problema das nacionalidades e das etnias oprimidas do Estado czarista para o momento em que triunfasse a revolução bolchevique. Em 1904, escreveu Sobre o direito das nações à autodeterminação; em 1916, escreveu sobre $A$ revolução socialista e o direito das nações à autodeterminação. $\mathrm{O}$ autor afirma ainda que a noção de colonialismo interno não tinha aparecido até o Congresso dos povos do Oriente ${ }^{15}$ celebrado em Baku em setembro de 1920; momento em que os muçulmanos da Ásia, "verdadeira colônia do império russo" fizeram os primeiros esboços do que chamaram "o colonialismo no interior da Rússia" (GONZÁLEZ CASANOVA, 1963, p. 04).

\footnotetext{
12 "Na época em que viviam no Chaco, os Terena eram agricultores, combinando a agricultura com a caça e coleta. O ambiente em que viviam se caracteriza como uma planície com pequenas elevações e de clima ameno" (ALTENFELDER, 1949, p. 277).
}

13 "Os dados de campo foram coletados graças a técnicas de forçar a "memória tribal", recorrendo-se a informantes idosos, uma vez que a estrutura social tradicional não logrou sobreviver ao contato interétnico" (OLIVEIRA, 1986, p. 17).

${ }^{14}$ Lênin tentou "evitar a preponderância da Rússia sobre as demais unidades nacionais" (Lênin, 1985: 360, Tomo XXXVI). Fez ver que a Internacional Socialista devia "denunciar implacavelmente as contínuas violações da igualdade das nações e garantir os direitos das minorias nacionais em todos os Estados capitalistas" (Lênin, 1985: 294-97, Tomo XXXIII). No fim da guerra colocou a necessidade de uma luta simultânea contra o paneslavismo, o nacionalismo e o patriotismo russo (que constituíam a essência do imperialismo russo) e em 1920 fez um enérgico chamado para pôr atenção na "questão nacional" e no fato de que Rússia "em um mesmo país, é uma prisão de povos" (Lênin citado por Gallissot, 1981: 843, Tomo III, Parte II, apud, GONZÁLEZ CASANOVA, 2007, p. 04).

15 "Em 1 de Setembro de 1920, na cidade de Baku, a capital do Azerbaijão, um Congresso de Representantes dos Povos do Oriente ocorreu o congresso participaram 1891 delegados dos seguintes países: Turquia, Pérsia, Egito, Índia, Afeganistão, Baluchistão, Kashgar, China, Japão, Coreia, Arábia, Síria, Palestina, Bucara, Khiva, Daguestão, Cáucaso Norte, Azerbaijão, Armênia, Geórgia, Turquestão, Ferghana, a Região Autônoma de Carmúquia, a República Tártara e o Distrito do Extremo Oriente". Disponível em https://www.novacultura.info/single-post/2016/12/19/Um-manifesto-aos-povos-do-Oriente , acesso em 27.10.2017. 
Eremites de Oliveira (2016), apoiado nos escritos de González Casanova (1963), afirma que as "origens do colonialismo interno remontam ao processo de independência de ex-colônias europeias e à constituição dos estados-nações (Estados modernos) nas Américas e em outros continentes"16. E informa que esta categoria analítica foi inicialmente difundida na antropologia brasileira nos anos 1960 por Cardoso de Oliveira (1978), apoiado em Balandier (1993 [1951]), González Casanova (1963) e outros autores; servindo de "base para o antropólogo formular a teoria da fricção interétnica, uma ruptura com a abordagem culturalista e com o paradigma da aculturação que influenciavam os estudos etnológicos"17.

Assim, a noção de colonialismo interno torna-se relevante para analisar o processo de usurpação dos territórios Terena, sob a conivência do Estado. É preciso ainda entender que essa significativa perda do território impactou diretamente a vida dessa população, sendo uma situação histórica ${ }^{18}$ caracterizada pelo avanço das frentes de expansão e implantação de projetos desenvolvimentistas no Mato Grosso do Sul, traduzindo-se num sistema estruturante de relações de poder, práticas estatais e invenção legal para legitimar a expropriação de territórios indígenas. Neste ponto, apoio-me ainda na noção de situação histórica desenvolvida por João Pacheco de Oliveira (2015, p. 49), quando enfatiza que esta não se confunde com a ideia historicista de "fases" ou "etapas", mas sim a uma "descrição singularizante de um processo através de seus momentos no tempo". É com base neste aporte teórico que na mina tese de doutorado suscitei outros "tempos" da história Terena descrevendo os processos e seus atores sociais na historiografia indígena.

Neste sentido, retomo aqui o argumento suscitado por representantes antíindígena, que na tentativa de defender um suposto direito de propriedade em detrimento dos direitos originários da população Terena, apoiados inclusive, em escritos de antropólogos e historiadores, defendem que os Terena não teriam direito aos seus territórios porque são

\footnotetext{
16 "Foi nesse momento que as elites criollas ascenderam ao poder central e passaram a ter controle sobre o aparato estatal, conforme explicado por González Casanova (2006). No caso americano, tais elites geralmente descendem de europeus e não se identificam com as populações indígenas. Portanto, quando surgiram novos estados-nações nesta parte do globo, a partir da segunda metade do século XVIII, os mesmos não foram constituídos em atenção aos direitos dos coletivos originários que estavam aqui antes da existência de países como Argentina, Brasil, Cuba, México e Estados Unidos" (EREMITES DE OLIVEIRA, 2016, p. 359).

${ }^{17}$ Cf. Eremites de Oliveira (2016).

18 "Uma situação histórica se compõe de um conjunto determinado de atores e forças sociais, cada um desses provido de diferentes recursos, padrões de organização interna, interesses e estratégias. A intenção primeira é de proceder a um inventário de elementos com referência empírica direta e suas características, em um segundo momento buscando apreender as regras por meio das quais se imprime uma ordem ao relacionamento desses agentes, definindo-se as condições e o alcance de possíveis alianças e de áreas de conflito" (OLIVEIRA, 2015, p. 49).
} 
oriundos de outro país, no caso o Paraguai. Valem-se justamente do argumento de que os Terena vieram do denominado "Chaco paraguaio", como escreveram vários antropólogos. No entanto, é preciso refletir sobre a invenção das fronteiras nacionais, o estabelecimento de fronteiras internas e também frisar que antes mesmo dessas invenções estatais, os povos indígenas já estavam ali. No caso dos Terena, tem-se um argumento específico adicional, pois até o acontecimento da guerra com o Paraguai, parte do território que hoje pertence ao Brasil era paraguaio, e foi justamente os Terena que lutaram na guerra defendendo o que hoje se denomina território brasileiro.

E ainda, o levantamento preliminar dá conta de que o denominado "Chaco" corresponde justamente a parte do território hoje reivindicado pelos Terena, território este que vai além das fronteiras nacionais, abrangendo o Brasil, Paraguai, Bolívia e Argentina. Assim, essa tentativa de desqualificar a reivindicação do Povo Terena é uma atitude colonial e a partir desse pressuposto é possível desqualificar esses argumentos. Nessa perspectiva, tendo em vista que a colonização europeia e colonização interior tendem a realizar expropriações e saques de territórios, tendem também a promover a invisibilidade dos povos indígenas enquanto sujeitos de direitos originários.

\section{O Conselho Terena e mobilização política}

Desde 2012, as lideranças do povo Terena, organizado por meio do Conselho do Povo Terena - organização tradicional constituído por caciques e líderes de retomadas -, tem feito o enfrentamento na luta pelos seus direitos, especialmente no que diz respeito ao reconhecimento formal dos territórios tradicionalmente ocupados. Através da realização da Hanaiti Ho’únevo Têrenoe (Grande Assembleia Terena), as lideranças têm discutido e tomado decisões importantes sobre o território, saúde, educação, sustentabilidade e política de representação nas instâncias institucionais.

Assim, no ano de 2012 realizamos várias reuniões locais na terra indígena Taunay/Ipegue tendo como pauta principal a questão fundiária. A presença dos professores indígenas era marcante juntamente com vários outros jovens que estavam cursando graduação nas universidades de Mato Grosso do Sul. Um momento importante, tido como primeira reunião local aconteceu na aldeia Água Branca em março de 2012, tendo como principais articuladores Lindomar Ferreira, Luiz Henrique Eloy Amado, Elvisclei Polidório, Dionédson Candido e Zacarias Rodrigues, estando presentes várias lideranças da terra indígena Taunay/Ipegue (ex-caciques, rezadores, professores indígenas, acadêmicos, movimento de 
mulheres) e lideranças da Comunidade Mãe Terra do município de Miranda. A reunião contou com a participação de representantes do Ministério Público Federal, o Procurador Emerson Kalif Siqueira; representante da Advocacia Geral da União, a Procuradora Federal Adriana de Oliveira Rocha e Assessoria Jurídica do Conselho Indigenista Missionário, advogado Rogério Batalha. Foi neste episódio que foi constituída uma comissão de lideranças com o fito de levar a mesma discussão para as demais comunidades, foi constituída a denominada "Comissão Fundiária" tendo como primeiro responsável (ou presidente conforme denominação adotada pelas próprias lideranças) o Cacique Ramiro Luiz Mendes (Cacique Chico Ramiro) da aldeia Ipegue.

Após, foram marcadas outras reuniões locais em cada comunidade na tentativa de mobilizar todas as lideranças para o movimento de luta pela terra, em especial dos demais caciques que até então não estavam participando. As próximas reuniões aconteceram nas aldeias Bananal e Morrinho, da terra indígena Taunay/Ipegue. Ao final dessas duas reuniões a mobilização em torno do território era consensual, e as divisões de grupos de interesses que até então predominavam se uniram em torno da discussão territorial. Neste momento da mobilização já havia a participação de caciques e consequentemente maior aderência por parte da comunidade em geral.

Nas reuniões que aconteceram em Bananal e Morrinho foi debatida a situação jurídica dos territórios tradicionais e, após a análise do andamento do procedimento administrativo de demarcação e da ação judicial que havia suspendido a demarcação, a comunidade chegou ao entendimento que era preciso adotar formas próprias de mobilização social. Foi então marcada uma grande reunião e convidado todos os caciques. Os Terena Lindomar Ferreira, Zacarias Rodrigues, Dionédson Candido, Elvisclei Polidório e Luiz Henrique Eloy Amado saíram em peregrinação nas comunidades convidando as lideranças: Terra indígena Taunay/Ipegue, Terra indígena Buriti; Terra indígena Limão Verde; Terra indígena Cachoeirinha; Terra indígena Pilad Rebuá; Terra indígena Lalima; Terra indígena Nioaque e comunidades indígenas do município de Campo Grande.

Assim, nos dias $1^{\circ}, 2$ e 3 de junho de 2012 foi realizada a primeira grande reunião Terena contando com a participação de quase a totalidade dos caciques Terena e lideranças Kadiwéu e Kinikinau. Na abertura da Assembleia a anciã Dona Nena, da Aldeia Água Branca, afirmou que desde a guerra do Paraguai os Terena, os Kadiwéu e os Kinikinau não se reuniam, e reforçou dizendo que ali não se tratava de uma simples reunião, mas de uma Hánaiti Ho’únevo Terenoê (Grande Assembleia do Povo Terena), conforme consta no 
documento final da assembleia ${ }^{19}$.

Figura: Caciques e lideranças tomando decisões durante Assembleia na Aldeia Imbirussú Junho de 2012

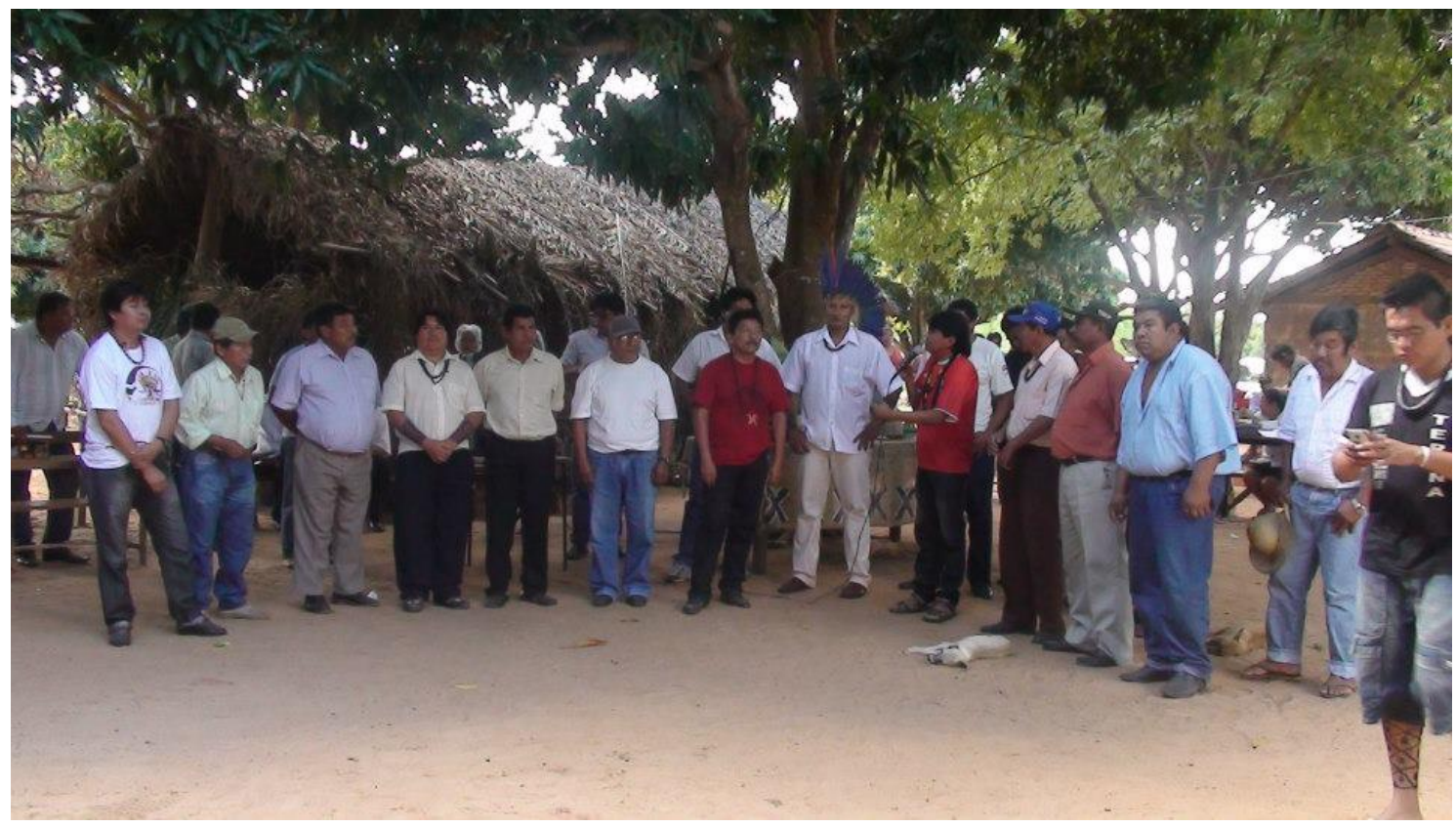

Fonte: Arquivo do pesquisador.

$\mathrm{Na}$ foto: Cacique Alvisore da Aldeia Ipegue, Cacique Alceri da Aldeia Lagoinha, Cacique João da Silva da Aldeia Lalima, Cacique Isaias Francisco da Aldeia Água Branca, Cacique Claudio Lipú da Aldeia Imbirussú, Lindomar Terena, liderança da retomada Charqueada, Cacique Benígno da Aldeia Morrinho, Cacique Fernando Antonio da Silva da Aldeia Argola e professor Elvisclei Polidório.

O documento final da primeira assembleia terena expressa à conjuntura dos desafios postos aos direitos indígenas abordando as proposições legislativas em tramitação contra os povos indígenas tais como: Proposta de Emenda Constitucional n. 215 (também conhecida como PEC 215), Portaria n. 303 da AGU, PL 1.610 que trata da mineração em terras indígenas, Projeto de Lei 227, dentre outros. A carta final expressou decisão tomada no que diz respeito à organização do movimento terena, afirmando que somente os representantes legítimos das comunidades indígenas poderiam falar em nome delas, desmantelando as vozes distantes da realidade das comunidades, mas que se apresentavam como representantes destas ${ }^{20}$.

\footnotetext{
${ }^{19}$ Fizeram parte da secretaria da assembleia, redigindo o documento final, os professores indígenas Wanderley Dias Cardoso, Dalila Luiz, Delair Vargas e Nilza Terena.

${ }^{20}$ Durante esta assembleia os caciques de várias comunidades reforçaram a necessidade de se ter um Conselho de Terena que congregasse todas a lideranças indígenas que estavam em suas comunidades vivenciando as lutas cotidianas. As vozes foram duras em relação ao parente Marcos Terena que se apresentava como representante de todos os povos indígenas do Brasil nacional e internacionalmente e, iniciou-se a desconstrução dessa
} 
Outro aspecto importante, diz respeito à aproximação das lideranças de retomadas, dos caciques das aldeias, dos professores indígenas e dos acadêmicos indígenas. Os Terena têm presença marcante nas universidades e em algumas instâncias políticas importantes seja integrando a gestão pública municipal ou estadual, no órgão indigenista oficial, nas escolas e universidades. No entanto, até aquele momento estavam dispersos no que diz respeito à pauta referente aos seus territórios tradicionais.

No que se refere aos acadêmicos indígenas tinha-se a plena convicção que para os povos indígenas de nada adiantaria seus jovens irem para as universidades se estes não derem alguma devolutiva para as suas comunidades. Foi a partir de então que se iniciaram no âmbito do Programa Rede de Saberes ${ }^{21}$ : Permanência de indígenas no ensino superior, diversos encontros temáticos visando refletir sobre os conhecimentos "científicos" e o conhecimento tradicional, buscando encontrar caminhos para um diálogo entre os estudantes e suas lideranças.

Figura: Reunião das lideranças com acadêmicos indígenas na Aldeia Buriti - Dezembro de 2012

representação que não tem base na comunidade e, portanto, distante da realidade vivida pelas comunidades Terena de Mato Grosso do Sul. Tal posição foi confirmada no documento final da Cúpula dos Povos durante a $\mathrm{RIO}+20$, onde todos os povos presentes repudiaram a posição do parente Marcos Terena.

${ }^{21}$ O Programa "Rede de Saberes" é uma ação afirmativa realizada por quatro universidades do estado Mato Grosso do Sul, no caso a Universidade Católica Dom Bosco (UCDB), a Universidade Estadual do Mato Grosso do Sul (UEMS), a Universidade Federal do Mato Grosso do Sul (UFMS) e a Universidade Federal da Grande Dourados (UFGD), que tem como objetivo apoiar em especial a permanência na educação superior de estudantes indígenas da região. Inicialmente realizado pela UCDB e pela UEMS a partir do repasse de recursos da Fundação Ford feito pelo Projeto Trilhas de Conhecimentos entre 2004-2007, o programa passou a beneficiar também estudantes da UFGD e da UFMS a partir de 2008. O responsável pela coordenação geral do programa é o historiador Antônio Brand, professor da UCDB.A estimativa de que o projeto vem atendendo mais de 1.200 estudantes universitários indígenas de povos do Mato Grosso do Sul evidencia a importância dessa ação afirmativa para a rede participação de populações indígenas no ensino superior brasileiro. Dentre as ações desenvolvidas pelo programa para apoiar a trajetória dos estudantes indígenas, podem ser listadas a realização de levantamentos sobre a situação e sobre as demandas dos estudantes indígenas do MS, a capacitação de docentes, funcionários e estudantes das universidades participantes acerca de questões envolvendo a situação dos povos indígenas no Brasil, criação de laboratórios de informática na UEMS e na UCDB para uso dos acadêmicos beneficiados pelo programa, etc. No âmbito da UCDB, foram realizadas outras importantes ações específicas, como a criação do site do programa, o incremento de materiais ao centro de documentação Teko Arandu, e o financiamento de projetos de pesquisa e extensão destinados a produção acadêmica de estudantes indígenas. Disponível em http://neppi.org/rededesaberes/ Acesso em 25/11/2017. 


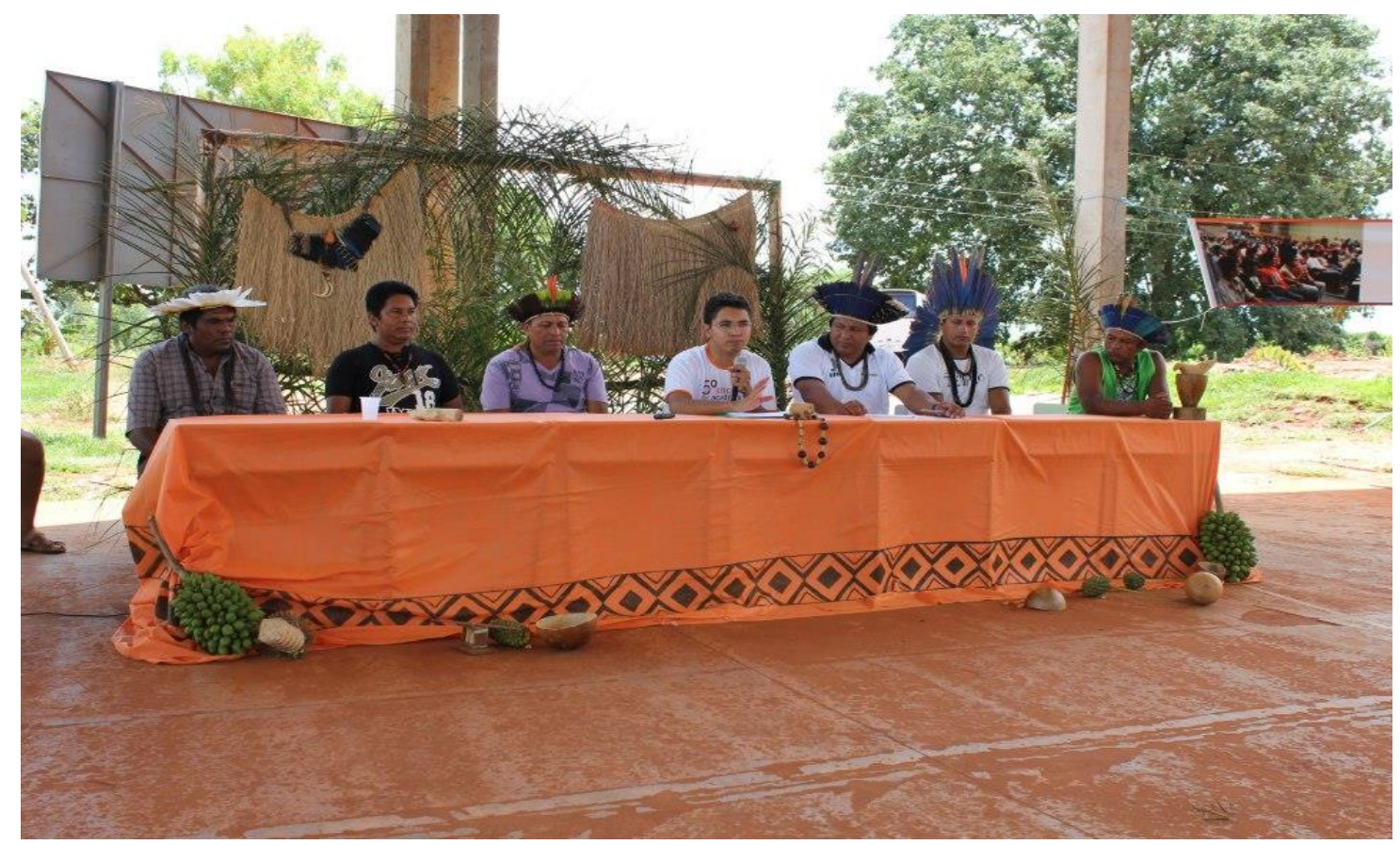

Fonte: NEPPI/UCDB

Os encontros com lideranças surtiram efeito positivo para a luta das comunidades indígenas, tanto no que diz respeito à questão fundiária, mas também para a saúde e educação. O próprio Conselho do Povo Terena dispõe de uma comissão de jovens que tem por função participar ativamente das demandas do movimento indígena. Esta participação tende a qualificar a luta, especialmente em relação à mobilização e visibilidade dessas demandas por meio de notas, vídeos e redes sociais. Segundo relato das lideranças da Terra Indígena Buriti a participação dos professores e acadêmicos na luta pela terra garante também uma proteção aos caciques e líderes de retomadas, pois estes fazem uma espécie de proteção de suas lideranças.

Figura: Fluxograma demonstrando a organização interna com a participação dos professores

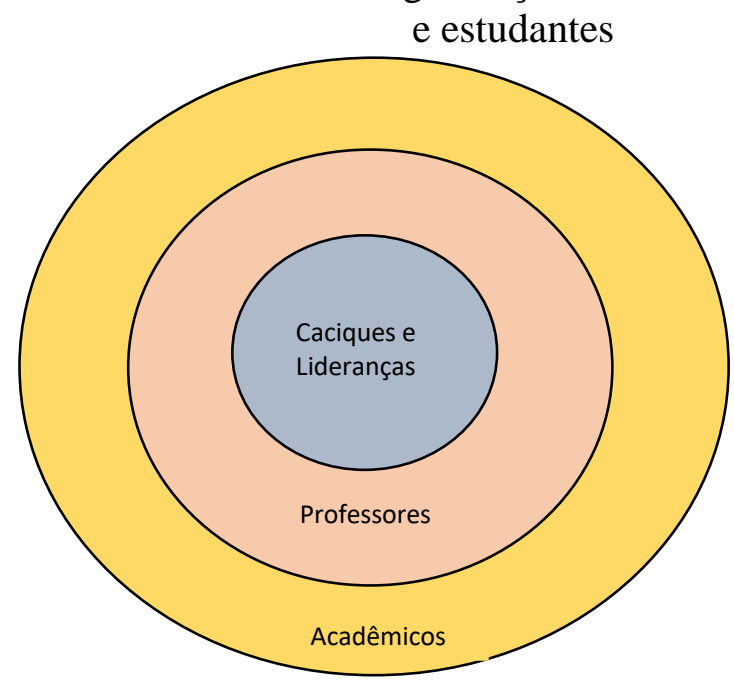


Assim a liderança não ficaria exposta diante da histórica violência perpetrada contra líderes indígenas que estão na luta pela terra e, tanto os professores quanto acadêmicos podem contribuir com a demanda de sua comunidade, valendo-se cada um do conhecimento adquirido na universidade. Nos últimos tempos o que tem sido notório é o papel de advogado indígena, do profissional da comunicação, de profissionais da área das ciências da terra e professores indígenas, pois estes são fundamentais nos primeiros dias de uma retomada. As assembleias têm se transformado num espaço importante visto que não têm apenas debatido a questão territorial, mas abrangem a educação, saúde, meio ambiente, sustentabilidade, representação política, juventude indígena e demandas das mulheres. Motivo pela qual têm contado com a participação de organismos tidos como aliados da luta dos povos indígenas.

Figura: Conselho Aty Guasu Guarani Kaiowá na Assembleia Terena

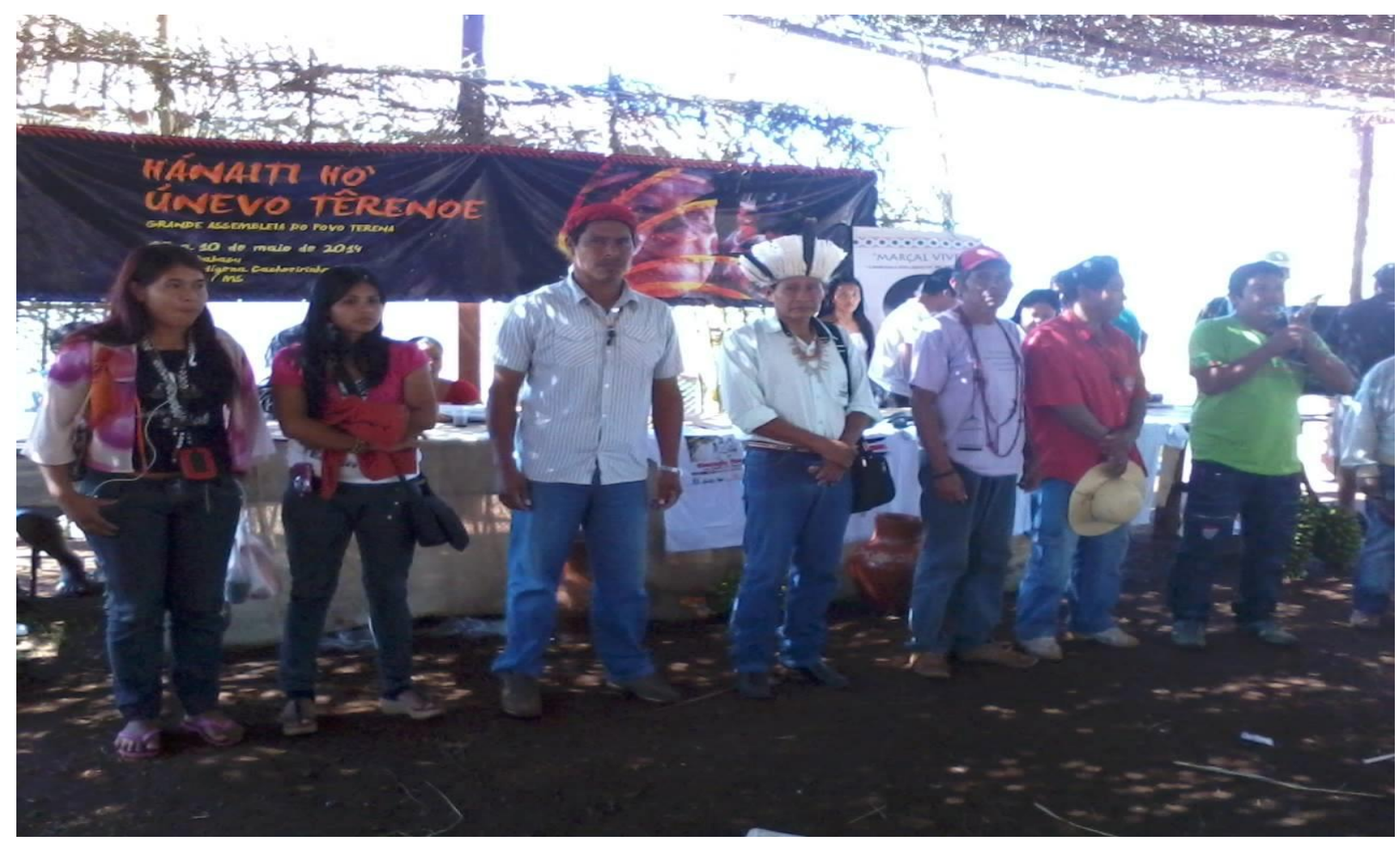

Fonte: Arquivo do pesquisador

Desde as primeiras Assembleia Terena o Conselho Aty Guasu Guarani Kaiowá tem participado com número significativo de lideranças, anciões e jovens. A própria estrutura do conselho foi pensada tendo como exemplo o Conselho Aty Guasu e, nas primeiras reuniões as lideranças Terena contaram com reflexões importantes trazidas por Otoniel Ricardo, liderança Guarani. Outro registro importante é o fato das Assembleias Terena 
sempre contarem com a participação de lideranças de outros povos indígenas no sentido de compartilhar experiências. Na Assembleia que ocorreu na Terra Indígena Buriti em maio de 2013, os líderes Babau Tupinambá e Nailton Pataxó, ambos do estado da Bahia participaram ativamente das discussões e deram grandes contribuições para a luta dos Terena de Mato Grosso do Sul. Fato é que as assembleias terena têm discutido os principais desafios aos direitos dos povos indígenas, tendo pautado a luta em âmbito nacional, sendo seus documentos finais, verdadeiros registros da situação vivenciada pelas comunidades indígenas e expressão de resistência ao modelo de desenvolvimento adotado pelo Estado brasileiro.

Figura: Leitura do documento final da Assembleia Terena em Babaçu

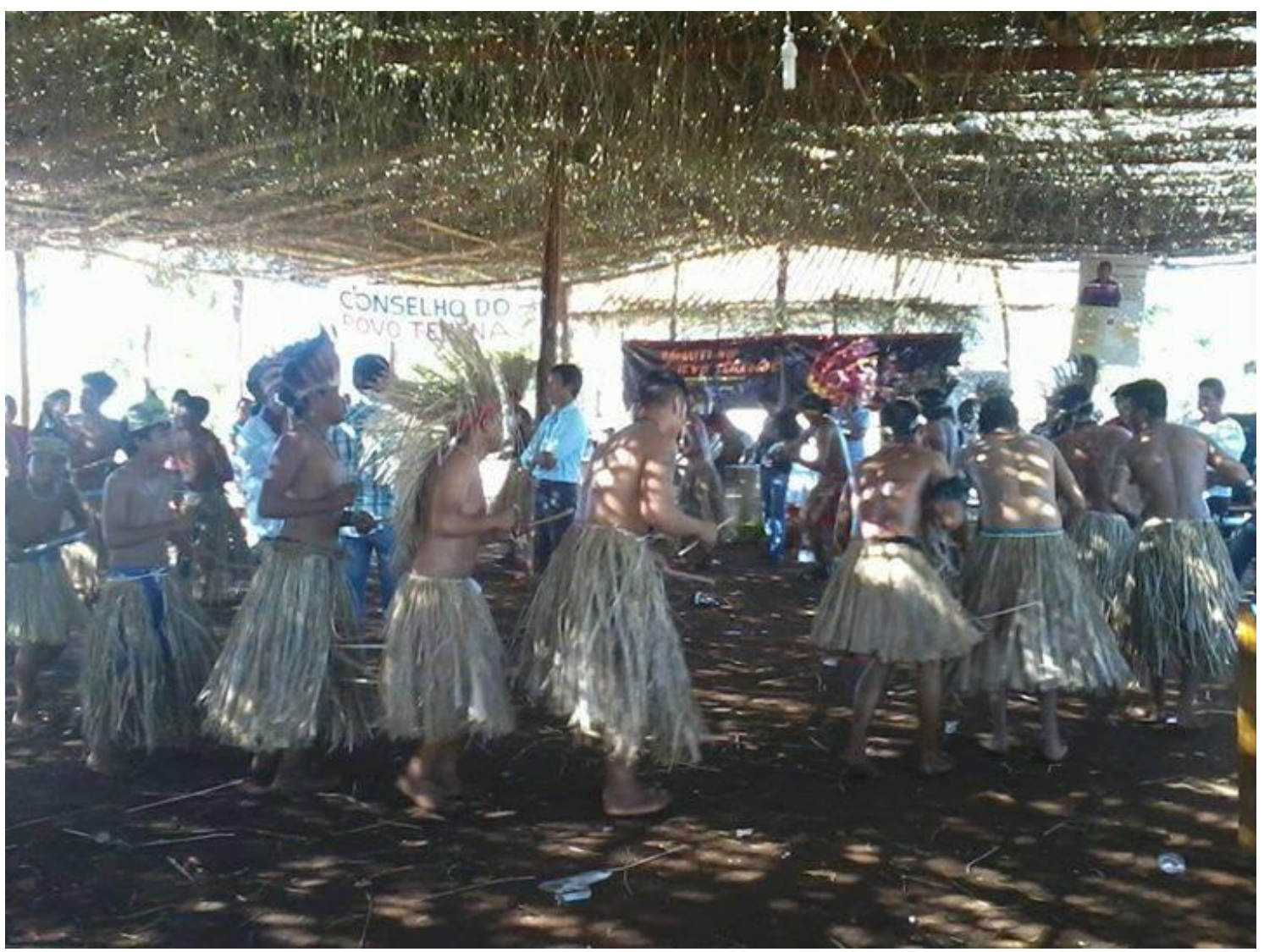

Fonte: Arquivo do pesquisador

No centro, Cacique Branco da Aldeia Babaçu, o advogado Terena Luiz Eloy e Nailton Pataxó fazendo a reza no documento final.

Após a primeira grande assembleia, outras grandes reuniões foram realizadas entre 2014 e 2017:

- $\quad 2^{a}$ Assembleia Terena - Aldeia Moreira, na TI Pilad Rebuá, em novembro de 2012;

- $\quad 3^{\text {a }}$ Assembleia Terena - Acampamento Terra Vida, na TI Buriti, em maio de 2013;

- $4^{a}$ Assembleia Terena - Aldeia Brejão, na TI Nioaque, em novembro de 2013;

- $5^{a}$ Assembleia Terena - Aldeia Babaçu, na TI Cachoeirinha, em maio de 2014; 
- $6^{\mathrm{a}}$ Assembleia Terena - Aldeia Lalima, na TI Lalima, em novembro de 2014;

- $7^{a}$ Assembleia Terena - Aldeia Cachoeirinha, na TI Cachoeirinha, em maio de 2015;

- $8^{a}$ Assembleia Terena - Aldeia Água Branca, na TI Nioaque, em março de 2016;

- $9^{a}$ Assembleia Terena - Aldeia Bananal, na TI Taunay-Ipegue, em novembro de 2016;

- $10^{a}$ Assembleia Terena - Aldeia Buriti, na TI Buriti, em junho de 2017;

- $11^{\mathrm{a}}$ Assembleia Terena - Aldeia Água Branca, na T.I. Taunay-Ipegue, em novembro de 2017.

A categoria "terra tradicionalmente ocupada" foi reconhecida pelo texto constitucional de 1988 e vem sendo objeto de luta dos povos indígenas de Mato Grosso do Sul, especialmente pelos Terena, Guarani, Kaiowá e Kadiwéu. Mesmo a Constituição de 1988 reconhecendo o direito originário dos povos indígenas aos seus territórios tradicionais e impondo prazo de cinco anos para a demarcação e homologação de todas as TIs, ainda hoje várias comunidades estão fora de seus territórios aguardando o reconhecimento jurídicoformal de suas terras.

A conduta territorial que antes usurpava, invadia e despejava comunidades inteiras de seus territórios tradicionais, hoje se traduz numa "conduta política", sistematizada no conjunto de articulações estatais imbricadas em todas as instâncias de poder da máquina estatal, com o nítido objetivo de impedir o reconhecimento desses territórios tradicionais. Os dispositivos constitucionais que reconhecem essa diversidade de territorialidades - Estado pluriétnico -, um processo de ruptura e de conquista, não resultaram em nenhuma adoção de política étnica e nem de ações governamentais capazes de reconhecer efetivamente esses territórios.

Nessa luta pelo território, diferentes estratégias permeiam o interior das comunidades, como as retomadas e questões externas, como ações governamentais. Fica nítida, por meio delas, a distinção entre as formas de territorialidade estatais, baseadas no reconhecimento formal, e as formas de territorialidade indígena, como as retomadas e autodemarcações. Na territorialidade estatal, que tem por objetivo reconhecer formalmente determinado território a um determinado povo indígena, é preciso entender como o Estado brasileiro regula e reconhece esses territórios. Na década de 1980, pesquisadores ligados ao "Projeto de Estudos sobre Terras Indígenas no Brasil: invasões, uso de solo e recursos naturais (PETI)", desenvolvido no Museu Nacional, procuraram debruçar-se sobre os modos como o Estado brasileiro formulava e definia as Terras Indígenas. É justamente neste plano que se abre a possibilidade de refletir, na tentativa de compreender como a "conduta política" atual não tem contemplado os povos indígenas e, consequentemente, os seus territórios tradicionais. 
As áreas ocupadas pelo povo Terena são reservas criadas na época do Serviço de Proteção ao Índio (SPI). Tem-se como principais entraves à demarcação dos territórios indígenas a judicialização das demarcações e o modelo de "desenvolvimento" adotado pelo Estado brasileiro, opção que não contempla as comunidades, ainda vistas como empecilho ao dito "desenvolvimento". No que tange à judicialização ${ }^{22}$, são latentes as inúmeras ações judiciais em trâmite perante a Justiça Federal de Mato Grosso do Sul, bem como os recursos interpostos perante o Tribunal Regional Federal da $3^{\mathrm{a}}$ Região, segunda instância de jurisdição. Como se sabe, o procedimento de demarcação de TIs está previsto para tramitar na via administrativa, iniciando-se na Funai e sendo concluindo com expediente da presidência da República (atos do poder Executivo). No entanto, com as ações intentadas pelos interessados na não demarcação, os procedimentos ficam paralisados por força de decisões judiciais, baseadas apenas em argumentos jurídicos de cunho civilista (aplicando o Código Civil), enquanto o direito dos povos indígenas foi tratado com profundidade pelo direito constitucional (Constituição Federal).

Diante da inércia do poder público em cumprir a determinação constitucional de demarcar as TIs, o Conselho do Povo Terena, por meio de seus caciques e lideranças, deliberou a imediata retomada de seus territórios. Nesta esteira, nos últimos cinco anos os Terena reocuparam aproximadamente 45 mil hectares de terras, constituindo inúmeros acampamentos indígenas. No município de Dois Irmãos do Buriti, temos as retomadas 10 de maio, Pahô Sîni, Terra Vida e Cambará. No município de Miranda estão as retomadas Maraoxapá, Mãe Terra, Charqueada e Kuixóxono Utî. Em Aquidauana estão as retomadas Esperança, Maria do Carmo, Cristalina, Ouro Preto, Persistência, Capão da Arara, Ipanema, Touro e Santa Fé.

\footnotetext{
22 "O levantamento das ações judiciais demonstra justamente essa tendência do judiciário federal de Mato Grosso do Sul. Em levantamento feito em 2015, constatou-se que na Justiça Federal de Mato Grosso do Sul estavam em trâmite aproximadamente 388 processos judiciais que versavam sobre demarcação de TI e demais conflitos possessórios. Desse total, 154 processos tramitavam na subseção judiciária de Campo Grande; 73 processos em Dourados; 93 em Ponta Porã; e 68 em Naviraí. Estas são apenas ações tramitando em primeira instância, sem contar outras centenas de recursos pendentes nos tribunais de segunda instância. No Supremo Tribunal Federal (STF) localizamos 13 ações judiciais envolvendo demarcação de TIs. Há casos em que o Estado de Mato Grosso do Sul ingressa como parte no processo, atuando como assistente litisconsorcial do fazendeiro; o que faz a ação ser deslocada da Vara Federal de primeira instância para o STF. Esta sistêmica ação por parte do Estado (leia-se: governador) tem o nítido objetivo de levar o processo para o STF e, consequentemente, aumentar a demora por uma decisão do poder Judiciário. Como a judicialização tem sido um dos principais entraves às demarcações, são várias as manobras processuais para o retardamento da prestação jurisdicional, entre eles, o ingresso do Estado como parte nos processos" (ELOY AMADO; RICCI TENÓRIO, 2016).
} 
É justamente neste contexto de conflito fundiário que o indígena Oziel Gabriel, liderança Terena, foi morto na manhã do dia 30 de maio de 2013, depois de ser gravemente ferido por projétil de arma de fogo em uma área retomada pelo povo Terena pertencente à TI Buriti, declarada em 2010 como de ocupação tradicional. O episódio se deu quando a Polícia Federal, usando de um violento modus operandi desproporcional, em uma ação mal planejada, iniciou a execução da reintegração de posse da área ocupada pela comunidade, que vem sendo reivindicada pelo ex-deputado estadual Ricardo Bacha, com bombas de feito moral, spray de pimenta e tiros de armas letal e não letal. Em 2016, as investigações do Ministério Público Federal (MPF) concluíram que o projétil que atingiu Oziel partiu de uma arma da Polícia Federal. No mesmo ano, o líder Paulino Terena foi atacado em sua comunidade por quatro homens encapuzados. $\mathrm{O}$ atentado foi atribuído a produtores rurais da região, em disputa na justiça pela posse de territórios reivindicados pelos Terena. Importante lembrar que foi nesta mesma região que, em 4 de junho de 2011, um ônibus que transportava cerca de 30 estudantes terena, a maioria entre 15 e 17 anos, foi atacado com pedras e coquetéis molotov. Seis pessoas, incluindo o motorista, sofreram queimaduras e quatro foram internadas em estado grave. A estudante Lurdesvoni Pires, de 28 anos, faleceu, vítima de ferimentos causados pelas queimaduras. $\mathrm{O}$ ataque está intimamente ligado ao contexto da disputa pela demarcação de TIs.

O contexto de Mato Grosso do Sul é extremo ao ponto de a violência do campo se institucionalizar nas agências estatais e setores de representação do agronegócio. A violência é, ao mesmo tempo, velada e declarada. Foi assim que no final de 2013, a Associação dos Criadores de Mato Grosso do Sul (Acrissul) e a Federação da Agricultura e Pecuária de Mato Grosso do Sul (Famasul), com o apoio da bancada ruralista do Congresso Nacional, lançaram a convocação da realização do chamado "Leilão da Resistência", grande ato político que tinha como fim maior a arrecadação de fundos para a formação de uma grande milícia armada para fazer a segurança de propriedades rurais e promover ataques a comunidades indígenas.

O Conselho Terena e a Aty Guasu (Grande Assembleia dos povos Kaiowá e Guarani), ingressaram com ação judicial para barrar o "Leilão da Resistência". O processo foi distribuído à $2^{\mathrm{a}}$ Vara Federal de Campo Grande, e no dia 4 de dezembro de 2013, a juíza Janete Lima Miguel determinou que as entidades ruralistas se abstivessem de realizar o leilão argumentando que "esse comportamento por parte das rés [fazendeiros] não pode ser considerado lícito, visto que pretendem substituir o Estado na solução do conflito existente entre a classe ruralista e os povos indígenas" e que "tem o poder de incentivar a violência (...) 
e colide com os princípios constitucionais do direito à vida, à segurança e à integridade física".

Numa manobra processual, em menos de 48 horas depois, as entidades ruralistas conseguiram afastar a magistrada do caso e, após o tribunal nomear outro magistrado, o leilão foi liberado pelo juiz Pedro Pereira dos Santos. A decisão, no entanto, impôs condicionantes: “1) O dinheiro arrecadado com o leilão deveria ser depositado numa conta judicial e controlado pela Justiça; 2) Os leiloeiros deveriam discriminar os nomes dos arrematadores e os valores pagos; 3) A utilização dos recursos arrecadados com o leilão só poderá ser feita depois da Justiça ouvir o Ministério Público Federal (MPF) e as organizações indígenas Aty Guasu e Conselho Terena”.

É notório, de igual modo, o processo de criminalização de lideranças indígenas e aliados do movimento indígena em curso no Estado e no Brasil. Eu mesmo enfrentei, em menos de dois anos, processos disciplinares na Ordem dos Advogados do Brasil, seccional Mato Grosso do Sul (OAB/MS), um deles com pedido de cassação de meu registro como advogado, assinado pela Comissão do Agronegócio da entidade. A perseguição aumentou depois que atuei na ação judicial que suspendeu a realização do chamado "Leilão da Resistência”, criando obstáculos intangíveis aos realizadores do evento. Em março de 2014, os ruralistas também manejaram uma ação judicial para tentar impedir que eu defendesse minha dissertação ${ }^{23}$ de mestrado dentro da terra indígena, justamente porque tratava do direito territorial dos povos indígenas.

Nesta esteira, em 2015 foi instalada pela Assembleia Legislativa de Mato Grosso do Sul uma Comissão Parlamentar de Inquérito (CPI) para investigar o Conselho Indigenista Missionário (CIMI). Proposta pela deputada ruralista Mara Caseiro, esta CPI foi um verdadeiro instrumento de perseguição a indigenistas e lideranças indígenas do estado. A Justiça Federal em Campo Grande, atendendo pedido da Defensoria Pública da União, concedeu liminar suspendendo a CPI, no entanto, o Estado de Mato Grosso do Sul ingressou na demanda e recorreu ao Tribunal Regional Federal da $3^{\circ}$ Região, que suspendeu a liminar possibilitando que a CPI prosseguisse com os trabalhos. Importante registrar que o Conselho do Povo Terena foi a organização indígena mais perseguida por esta CPI. Ao final, como produto concreto desta CPI ruralistas, os deputados Paulo Correa e Mara Caseiro criaram o denominado "Fórum de Caciques" que segundo eles seria a instância de representação dos caciques junto ao governo. Na verdade, essa tática colonial se revelou mais como vez como 
forma de cooptação a algumas indígenas e perseguição a aqueles que estavam nas retomadas reivindicando seus direitos.

A luta do povo Terena é incansável. No final de 2015 foram surpreendidos pela decisão da Segunda Turma do Supremo Tribunal Federal que anulou a demarcação da única Terra Indígena terena demarcada após 1988, a TI Limão Verde, localizada em Aquidauana. A demarcação da TI Buriti também foi anulada pelo Tribunal Regional Federal da $3^{\circ}$ Região e inúmeras decisões liminares têm sido prolatadas em ações de reintegração de posse contra comunidades indígenas.

Entra em cena a discussão do chamado "marco temporal" suscitado pela primeira vez no STF no julgamento do caso da Raposa Serra do Sol. A tese defendida por parte da Segunda Turma do STF é a de que o direito dos povos indígenas à posse de seus territórios tradicionais teria como condição a presença das comunidades nas terras que reivindicam na data de promulgação da Constituição, 5 de outubro de 1988.

Outra possibilidade seria a comprovação do esbulho renitente, ou seja, a resistência das comunidades indígenas à invasão de seus territórios por meio do conflito físico ou reivindicando a posse na Justiça. Cabe salientar que os povos indígenas, o MPF e a Funai refutam esta tese inconstitucional, pois não é possível a sua aplicação no contexto de intensas violações que os povos indígenas foram alvo nesses mais de 518 anos.

Fica evidente que as decisões do poder Judiciário baseadas no marco temporal são carregadas de um racismo ambiental que contamina os poderes da República, já que a atual Constituição não limita os direitos originários dos povos indígenas a 5 de outubro de 1988 , pelo contrário: impõe prazo para que o Estado brasileiro conclua a demarcação desses territórios. Cabe registrar que Terra Indígena e posse nativa são conceitos mais amplos que permanência física em certo espaço territorial. Na perspectiva de terra tradicionalmente ocupada por esse ou aquele povo indígena, vale dizer, prevalece toda a área necessária à reprodução física e cultural do povo.

$\mathrm{O}$ povo Terena tem demonstrado forte resistência em sua história imbricada às ações estatais de que foram alvo, entretanto, seguem firmes, fortalecendo-se enquanto povo indígena e gritando a palavra de ordem "Poké'exa ûti!", "nosso território tradicional (nossa terra)". Pronunciando essas palavras é que, nos últimos anos, as lideranças terena têm retomado territórios tradicionais e resistido no difícil caminho da luta por seus direitos.

\section{Referências}


ALTENFELDER SILVA, Fernando. Mudança cultural dos Terena. In: Revista do Museu Paulista. Nova Série. Vol. III. São Paulo. 1949.

AZANHA, Gilberto. Resumo do relatório circunstanciado de identificação e delimitação da terra indígena Taunay-Ipegue. In: Processo FUNAI/BSB no. 0289/85. Brasília, FUNAI. Diário Oficial da União, 13 ago. 2004, p. 42, Seção 1.

BALANDIER, Georges. A noção de situação colonial. In: Cadernos de Campo, ano 3, n. 3. São Paulo: USP, 1993.

BALDUS, Herbert. Lendas dos índios Terena. In: Revista do Museu Paulista. Nova Série. Vol. IV. São Paulo. 1950.

BITTENCOURT, Circe Maria, LADEIRA, Maria Elisa. A História do povo Terena. Brasília: MEC, 2000.

CARDOSO DE OLIVEIRA, Roberto. Do índio ao bugre: o processo de assimilação dos Terena. 2. ed. Rio de Janeiro, Livraria Francisco Alves, 1976.

CARDOSO DE OLIVEIRA, Roberto. Urbanização e Tribalismo: a integração dos índios Terena numa sociedade de Classes. Rio de Janeiro: Zahar Editores, 1968.

ELOY AMADO, Luiz Henrique; RICCI TENÓRIO. Lilian Raquel . A luta do Povo Terena por seus territórios tradicionais: reflexões sobre demarcação, judicialização e mesa de diálogo. In: Guilermo Alfredo Johnson, Losandro Antonio Tedeschi, Marcos Antonio da Silva, Tchella Fernandes Maso. (Org.). América Platina - Dilemas, dispustas e rupturas. 1ed.Curitiba: Appris, 2016, v. 1, p. 39-54.

ELOY AMADO, Luiz Henrique. Pokéexa Ûti: o território indígena como direito fundamental para o etnodesenvolvimento local. 2014. 125 f. Dissertação (Mestrado em Desenvolvimento Local). Universidade Católica Dom Bosco, Campo Grande.

EREMITES DE OLIVEIRA, Jorge; PEREIRA, Levi Marques. Perícia antropológica e histórica da área reivindicada pelos Terena para a ampliação dos limites da Terra Indígena Buriti, municípios de Sidrolândia e Dois Irmãos do Buriti, Mato Grosso do Sul, Brasil. Autos no 2001.60.00.003866-3, 3a vara da 1a subseção judiciária de Mato Grosso do Sul, 2003.

EREMITES DE OLIVEIRA, Jorge de. Arqueologia de contrato, colonialismo interno e povos indígenas no brasil. Amazônica - Revista de Antropologia, [S.I.], v. 7, n. 2, p. 354-374, jul. 2016. ISSN 2176-0677.

GONZÁLEZ CASANOVA, P. 1963. Sociedad plural, colonialismo interno y desarrollo en América Latina. Revista del Centro Latinoamericano de Ciencias Sociales 6(3): 15-32.

MIRANDA. Claudionor do Carmo. Territorialidade e prática agrícola: premissas para o desenvolvimento local em comunidades Terena de MS. 2006. 121 f. Dissertação (Mestrado em desenvolvimento local) - Universidade Católica Dom Bosco, Campo Grande. 
OBERG, Kalervo. Terena Social Organization and Law. Trad. de S. M. S. Carvalho. Revista Terra Indígena, Araraquara, n. 33, p. 9-21, 1985.

OLIVIERA, João Pacheco de. Regime tutelar e faccionalismo. Política e Religião em uma reserva Ticuna. Manaus: UEA, 2015.

SÁNCHEZ LABRADOR, José. El Paraguay católico. Buenos Aires: Imprenta de Coni Hermanos, 1910 [1770].

TAUNAY, Visconde de. A retirada da Laguna: episódio da Guerra do Paraguai São Paulo: Martin Claret, 2005.

XIMENES, Lenir Gomes. A Retomada terena em Mato Grosso do Sul: oscilação pendular entre os tempos e espaços da acomodação em reservas, promoção da invisibilidade étnica e despertar guerreiro. Tese de doutorado. Dourados, MS: UFGD, 2017. 